it is hoped that in future more use will be made of these facilities. The premises were redecorated during the year, and they have a very pleasing appearance. As a result of the financial stringency, a certain amount of economy in the activities of the Society has had to be enforced during the year, but receptions were arranged for the delegates to two conferences-one on nucleic acids, organized by the Faraday Society, and the other by the General Assembly of the International Union of Pure and Applied Physics-and members of the Bureau of the International Council of Scientific Unions were also received on the occasion of their meeting in London in the spring. Of the three evening meetings held during the year, one consisted of scientific films on the petroleum industry, and another was a lively discussion on "The Science of Clothing". The third gathering was prompted by the occasion of the meeting in London of the Executive Committee of the International Geographical Union, and $a_{0}$ discussion was arranged on "World Population".

The Overseas Science Students Association, which was started two years ago with the help of the Student Department, Student Welfare Department and the Science and Engineering Department of the British Council, has continued to hold its regular weekly meetings.

Although there were few 'major' occasions, the principal function of the Society - to act as a dayto-day centre in London for all scientific workers, both from overseas and those resident in Britainwas maintained, for which no little credit is due to the secretary, Miss E. Simpson. The officers of the Society are: President, Prof. A. V. Hill; Honorary Secretaries, Prof. F. J. M. Stratton and Mr. A. Lang Brown; Treasurer, Prof. A. Haddow; Chairman of the Programme Committee, Mr. G. A. McMillan; and New Member of Council, Sir Lawrence Bragg.

\section{BUILDING RESEARCH STATION REPORT FOR 1953}

$\mathrm{T}$ HE report for 1953 of the Building Research Board, to which is attached the report of the director of building research, Dr. F. M. Lea, this latter taking up the major part of the publication (pp. 66. London: H.M.S.O., 1954 ; $3 s .6 d$. net), is chiefly impressive for the very great amount and variety of research that has been undertaken at the Building Research Station, Garston, near Watford. Perhaps this is not altogether surprising, since the staff at the Station numbers more than four hundred, half of whom are officers in the scientific and experimental grades.

The director's report is divided into seven sections entitled : materials; design and performance of structures; soil mechanics; building operations ; efficiency of buildings; the Scottish Laboratory; and Colonial housing and building research. In materials alone, the problems are becoming exceedingly varied and complicated as more and more different sorts of materials are invented and developed. But, of course, building research does not end with materials. 'There are the various types of building, from small dwelling-houses to large industrial premises, and it is with regard to the latter that many interesting developments are taking place, particularly in such media as prestressed concrete. Then, too, there is the question of building methods, productivity and costs, and the development of mechanical aids in building, of which the railoperated tower crane is a case in point. The scope of building research extends to such problems as flooding, sea-defence banks and dams.

The Scottish Laboratory is more and more providing a means of extending investigations at the main Station, though there are particular Scottish problerns, such as the utilization of local stone. In Colonial research, the work revolves around the activities of the Colonial liaison officer, who has been making extensive tours, mainly in Africa, looking into problems and arranging for the right organization to work on them. As yet, the only body in Africa engaged exclusively on building research is the South African National Building Research Institute, but plans are being laid for building research to be undertaken in British West Africa, the French African Territories and the Belgian Congo, as well as a certain amount of work on materials in Kenya and Southern Rhodesia.

Finally, mention must be made of the Building Research Board's concern at the reduction in finance during 1953, which severely curtailed long-term and short-term research, leaving the resources more concentrated on advisory work and the practical application of research. The Board feels strongly that its function is to promote not only work of immediate use but also that which will yield returns in the more distant future, and it is to be hoped that the recent lifting of financial restrictions on the Department of Scientific and Industrial Research will be reflected in the allocations to building research.

\section{PLANT CULTIVATION IN SALINE AND BRACKISH WATER}

$T^{\mathrm{H}}$ $\mathrm{HE}$ raising of plants under saline conditions is a common problem in arid areas, where there is little leaching of the soil by rainfall and where the water available for irrigation has often a high salt content. In the fourth volume produced under the Unesco Arid Zone Programme*, the utilization of saline water is dealt with in three reviews, which not only provide a useful summary of existing information, but also, by emphasizing the gaps in our knowledge, serve as pointers to further research.

The first review, by Georges Grillot, of the Centre de Recherches Agronomiques, Rabat, Moroceo, is based on research carried out in Africa, Europe and the Middle East. It deals with the biological problems presented by the growth of plants in saline or alkaline environments, and includes a particularly thorough section on the use of saline water for irrigation. Some of the important data are concisely set out in nine appendixes, among which is a table of natural halophytes "indicative of the corresponding cultivability of domestic specios". One of the principal conclusions of the review is that both research and actual practice show that irrigation by saline water is not necessarily harmful. Certain types of soil, however, may be impoverished by even slightly saline water ; but since vegetation is tolerant of higher degrees of salinity, the problem is one for the soil chemist rather than directly for the biologist.

* Arid Zone Programme. Reviews of Research on Problems of H.M.S.O., 1954.) 1.75 dollars, 500 francs, $10 s .6 d$. 
The second review is by Dr. H. E. Hayward, director of the United States Salinity Laboratory, Riverside, California, and covers research in the Americas, Australia and India. The practical problems encountered in the various geographical regions receive a comprehensive treatment ; but more space is allotted to an interesting general account of basic physiological problems. Subjects discussed include the physiological basis for salt tolerance, the physiological basis for alkali tolerance, the effect of saline and alkali soils on plant growth, toxic effects of specific ions and salt tolerance in relation to germina. tion. It is concluded that one of the main effects of moderate levels of soil salinity is to limit water supply to the plant by increasing the osmotic pressure of the soil solution. This effect is intensified by an increase in soil moisture tension, and the combined effect, total soil moisture stress, conditions the growth of plants. Over and above the osmotic effect, each component of the saline solution may have some specific toxic effect which may vary among various genera, species and varieties of agricultural crops. Because of this specificity in salt tolerance, it is important to make a proper selection of crops for use on lands that are marginal because of salinity.

The third review, by Dr. Everett D. Howe, of the Faculty of Engineering, University of California, is restricted to a consideration of methods of purification of salt and brackish waters. The development of an economically feasible method of carrying out such a purification on a large scale is clearly of the greatest importance, but has evidently not yet been achieved.

The reviews are clearly written and although their main value will be to those engaged in the agricultural development of saline regions, they have much of interest for many readers, particularly for the plant physiologist or ecologist.

A. Altsopp

\section{HOUSEFLIES RESISTANT TO A GROUP OF CHLORINATED HYDROCARBON INSECTICIDES}

\author{
By Dr. J. R. BUSVINE \\ London School of Hygiene and Tropical Medicine
}

$I^{\mathrm{N}}$ general, DDT has been the subject of far more research than other chlorinated hydrocarbon insecticides and, in particular, this is true of investigations of insecticide-resistance in houseflies. It seems that resistance to the insecticides $\gamma$-BHC, chlordane, dieldrin, aldrin and toxaphene is quite distinct from DDT-tolerance. These compounds must have some factor in common, since selection by exposure to one of them raises the resistance of a fly strain to the others. Questions which now arise are: Is there a single defence mechanism which protects resistant flies from all these compounds; and what is the common factor which defines this group of insecticides?

As regards DDT tolerance, there is evidence of at least two defence mechanisms, which may be more or less developed in different strains of $\mathrm{fly}$, and thereby modify the type of resistance displayed. This has been exemplified by two strains of DDT. resistant flies, which showed marked differences in relative susceptibility to a range of DDT analogues ${ }^{1}$.

It seemed possible that a similar type of investigation might reveal whether resistance to the $\gamma$-BHC-chlordane group of chlorinated compounds was equally heterogeneous. The method used was to determine the exact degrees of resistance, to a series of related compounds, shown by four strains of flies from very different sources. The strains of houseflies used were : (1) Sardinia strain. Previous history in the field: DDT house-spraying throughout the island during 1947-50; chlordane added to the spray from 1948; laboratory colony started in November 1950. (2) England strain. Previous history in the field : from a refuse tip at Egham, treated with DDT during 1947-49; during 1951-53 treated with BHC; laboratory colony started in September 1953. (3) Omdurman (Sudan) strain. Previous history in the field : all pit latrines and other breeding sites near the town dusted with BHC during 194952 ; in 1950, many houses sprayed with DDT; laboratory colony started in March 1953, through the kindness of Dr. D. J. Lewis. (4) Uruguay strain. Previous history in the field: widespread use of BHC and DDT; laboratory colony started in 1951; a subcolony kindly sent to me by Mr. Newman, of Imperial Chemical Industries, Ltd., in January 1954. (5) Normal strain. Reared in the laboratory for many years and believed to be normally susceptible to insecticides.

Samples of males of the above strains were collected and, on the fresh specimens, the ratios head width/frons width were calculated, with the following results : Sardinia, $6 \cdot 81 \pm 0.44$; England, 5.98 i 0.38 ; Omdurman, $10.94 \pm \mathbf{1} \cdot 45$; Uruguay, $5 \cdot 17 \pm$ $0 \cdot 46$; normal, $5 \cdot 14 \pm 0 \cdot 46$. The Omdurman strain is clearly of the $M$. domestica vicina type, while the England, Uruguay and normal colonies are of the $M$. domestica domestica form. The Sardinia ratio is $a$ little high, but approximates to the latter. These figures agree with those of Sacca, though I find the difference between colonies of domestica and vicina to be more constant than he suggests. Thus, after a year in my laboratory, the Omdurman ratio was found to be $11 \cdot 14 \pm 1 \cdot 40$, so that it had not changed appreciably.

Measurements of relative resistance. Purified samples of the following seven compounds were kindly supplied by the Shell Co., Ltd. : $\alpha$ - and $\beta$ chlordane $(1,2,4,5,6,7,8,8$-octochloro-4, 7 -methano$3 a, 4,7,7 a$-tetrahydroidane); it is believed that $\alpha$ - and $\beta$-chlordane differ in regard to the position of chlorine atoms on carbons 1 and $2, \alpha$ being a trans-

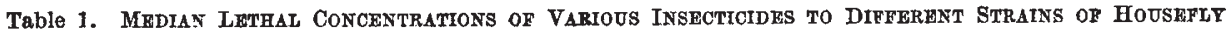

\begin{tabular}{|c|c|c|c|c|c|c|c|c|}
\hline \multirow[b]{2}{*}{ Fly strain } & \multicolumn{8}{|c|}{ Median lethal concentration (per cent) } \\
\hline & alpha & beta & Isodrin & Fndrin & $\gamma$-BHC & Aldrin & Dieldrin & DDT \\
\hline $\begin{array}{l}\text { Uruguay } \\
\text { Omdurman } \\
\text { Sardinia } \\
\text { England } \\
\text { Isaboratory }\end{array}$ & $\begin{array}{l}30 \\
18 \\
3 \cdot 5 \\
2 \cdot 0 \\
0 \cdot 04\end{array}$ & $\begin{array}{l}9 \\
4 \\
0 \cdot 3 \\
0 \cdot 4 \\
0 \cdot 018\end{array}$ & $\begin{array}{l}0.5 \\
0.35 \\
0.1 \\
0.09 \\
0.015\end{array}$ & $\begin{array}{l}0 \cdot 3 \\
0.2 \\
0.05 \\
0 \cdot 06 \\
0.009\end{array}$ & $\begin{array}{l}0 \cdot 8 \\
0 \cdot 5 \\
0 \cdot 09 \\
0 \cdot 1 \\
0.008\end{array}$ & $\begin{array}{l}7 \\
2 \\
0 \cdot 4 \\
0.23 \\
0 \cdot 007\end{array}$ & $\begin{array}{l}3 \\
1 \cdot 5 \\
0 \cdot 25 \\
0 \cdot 14 \\
0.005\end{array}$ & $\begin{array}{l}0.35 \\
0.6 \\
1.8 \\
1.0 \\
0.08\end{array}$ \\
\hline
\end{tabular}

